\title{
Preparation and Surface Analysis of PPY/SDBS Films on Aluminum Substrates
}

\author{
Lisete C. Scienza \\ Departamento de Engenharia Química, UCS
}

\author{
George E. Thompson \\ Corrosion and Protection Centre, UMIST (UK)
}

\begin{abstract}
Polypyrrole films were generated on high purity aluminum substrates under anodic polarization from aqueous electrolytes comprised of pyrrole and sodium dodecylbenzene sulfonate. The methods employed to characterize the polymer films included scanning electron microscopy, Fourier-transform infrared and Xphotoelectron spectroscopy and X-ray diffraction. PPY/SDBS films revealed nodular morphology with occasional appearing of "dendrites", high level of protonation, excess of counter-anions $\left([\mathrm{S}] /[\mathrm{N}]>\left[\mathrm{N}^{+}\right] /[\mathrm{N}]\right)$ and high degrees of disorder.
\end{abstract}

Keywords: Polypyrrole films, aluminium, electrosynthesis.

\section{Introduction}

In recent years, considerable attention has been dedicated to the study of synthesis, structures and properties of electroconducting polymers. The considerable interest in this class of materials has led to a large number of important applications such as rechargeable batteries, modified electrodes, capacitors and biosensors among many others ${ }^{[1,2]}$. For such applications, electrochemically synthesized polymer films on relatively cheap and commercially available metal substrates have attracted special interest.

Many studies related to polymerization of polypyrrole and polyaniline on oxidisable metals, such as carbon steel ${ }^{[3,4]}$, stainless steel ${ }^{[5]}$ and aluminum ${ }^{[6-7]}$, aimed at the corrosion protection of these substrates. Polymerization of conducting polymers on aluminum is particularly interesting due to possible use as capacitors $^{[3,8]}$ and rechargeable batteries ${ }^{[2,9,10]}$.

Several workers ${ }^{[6,7,10-14]}$ have reported the use of aluminum as substrate to support conducting polymers such as polypyrrole and polyaniline, from organic or aqueous electrolytes comprised of the monomer and different counter-anions. The main problem with the electrogeneration of polypyrrole onto reactive metals, such as aluminum, is related to the interference of the anodic/passive behavior of the metal during the polymerization process in the production of well-adhering polymer films. Oxide films formed on the metal surface act as barriers for electron transfer during electropolymerization, which give rise to inhibition of the process if a passive layer is formed or reduced current densities if a porous layer is formed ${ }^{[15]}$.

Polypyrrole is largely investigated due to its relatively good chemical and conducting stability as well as its relatively simple synthesis. The electrochemical synthesis usually employs galvanostatic, potentiostatic or potentiodynamic methods, which are also applied to characterize the electroactive behavior of the formed films ${ }^{[1,13,16]}$. The development of sophisticated electrochemical and surface analysis techniques, and their successful use in investigation of conducting polymers, has provided tools to determine important characteristics of the polymer systems. Physical-chemical characterization has considered Fourier-transform infrared spectroscopy (FT-IR), X-photonelectron (XPS) spectroscopy, scanning electron microscopy (SEM) and $\mathrm{X}$-ray diffraction $(\mathrm{XRD})^{[1,17,18]}$. The relationship between synthesis conditions and the properties achieved have improved the production of polypyrrole films designed for specific applications.

Autor para correspondência: Lisete C. Scienza Departamento de Engenharia Química, UCS, C. P.: 1352, CEP. 95001-970, Caxias do Sul, RS. E-mail: Icscienz@ucs.tche.br 
In this work, polypyrrole (PPY) films were galvanostatically synthesized on aluminum surface, in presence of a surfactant counter-anion. The produced polymer film was investigated further through the surface analysis techniques mentioned previously.

\section{Experimental}

\section{Polymer Synthesis}

Highly pure raffinal aluminum sheets $(0.0004 \pm 2 \%$ $\mathrm{Si}, 0.0006 \pm 2 \% \mathrm{Fe}, 0.0003 \pm 1 \% \mathrm{Cu}, 0.0015 \pm 3 \%$ $\mathrm{Mg},<0.0001 \% \mathrm{Mn},<0.0001 \% \mathrm{Ni},<0.0001 \% \mathrm{Cr}$, $<0.0002 \% \mathrm{Zn}$ and $<0.0001 \% \mathrm{Ti}$.), of $0.1 \mathrm{~cm}$ thickness were first mechanically polished with SC 600 grit paper, followed by vigorous washing and drying in cold air stream.

The synthesis solution was prepared employing pyrrole (Aldrich), which was first distilled under nitrogen and kept refrigerated until use. Dodecylbenzene sulfonic acid sodium salt (Fluka) was used as received. Deionised water was used as solvent and the solution of $0.1 \mathrm{M}$ of pyrrole (PY) and $0.1 \mathrm{M}$ of sodium dodecylbenzene sulfonate (SDBS) was prepared around one hour before the experiment. The chemical structure of the chemicals employed are shown in Figure 1.

Potentiodynamic polarization curves were performed in order to determine the potential (or current) when polymerization takes place. Potentials were applied from Eocp (open circuit potential) to $2000 \mathrm{mVsCE}$, at $2 \mathrm{mV} / \mathrm{s}$ scan rate. A three-electrode configuration electrochemical cell was employed where the working electrode was the aluminum sheet $(4 \times 1.5 \times 0.1 \mathrm{~cm})$, the counter-electrode was an austenitic stainless steel sheet and the reference electrode

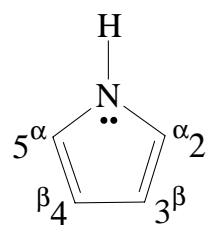

Pyrrole

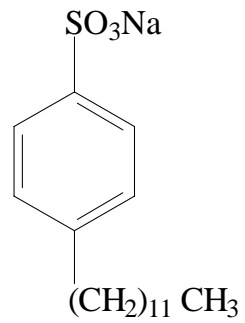

Dodecylbenzene Sulfonic Acid Sodium Salt
Figure 1. Chemical structure of the materials employed. was a saturated calomel electrode (SCE) and associated a Luggin capillary. The data were plotted in graphs of the potential applied ( $\mathrm{mVSCE}$ ) with the logarithm current density $\left(\mathrm{mA} / \mathrm{cm}^{2}\right)$.

For characterization of the polymer film, the specimens were submitted to the polymer synthesis, performed under $2 \mathrm{~mA} / \mathrm{cm}^{2}$ of current density over 20 minutes, in an aqueous electrolyte comprised of $0.1 \mathrm{M}$ of pyrrole (PY) and $0.1 \mathrm{M}$ of sodium dodecylbenzene sulfonate (SDBS). After synthesis the polymer-coated electrodes were rinsed thoroughly in deionised water, dried in cold air stream and placed in a desiccator prior to use in subsequent test.

\section{Polymer Characterization}

In order to check the adhesion of the polymer films on the electrodes, a cross cut adhesion test was performed for dried and wet specimens ("wet adhesion"). This test was based on ASTM D3359. A multiblade Erichen Multicross Hatch Cutter, model 295/I cutting tool, was employed to form a lattice pattern of six cutting edges and the results were classified according to the standard descriptions.

For SEM observations, the bulk specimens $(0.25$ $\mathrm{cm}^{2}$ ) were mounted on brass stubs using a highly conductive paint. No conducting coating was applied over the polymer surface. The specimens were examined in an ISI-DS 130 scanning microscope operating at $19 \mathrm{kV}$.

PPY powder was scratched from the metal electrodes surface and mixed with $\mathrm{KBr}$ to form pellets. Infrared spectra were recorded in the transmission mode using a Perkin-Elmer FT-IR spectrometer model 1760. To generate the FT-IR spectrum, 15 scans were performed for each sample.

XRD spectra of PPY-coated samples were recorded in the reflectance mode using $\mathrm{CuKa}$ radiation on a Philips X'pert MPD theta/theta system in the range of $3 \stackrel{2}{2} \geq 38^{\circ}$.

XPS measurements were made on a VG Scientific ESCALAB I spectrometer with AlKa source $(1486.6 \mathrm{eV})$, with electrical input power of $200 \mathrm{~W}$ and take-off angle of $10^{\circ}$. The pass energy was $100 \mathrm{eV}$ for qualitative surveys and $20 \mathrm{eV}$ for quantitative data. The pressure in the analysis chamber was maintained at $10^{-12}$ bar during measurements. The energy calibration of the system was checked with gold standard using the $4 \mathrm{f}_{7 / 2}$ line. The spectra were summed, smoothed and reconstructed using Gaussian-shaped components. 


\section{Results and Discussion}

Potentiodynamic polarization curves were performed to determine the anodic behavior of the aluminum electrodes in the absence and presence of the monomer. Based on the electrochemical potential-current response and visual observations, it is possible to predict the conditions (current and potential) in which the polymerization of pyrrole proceeds.

Based on the electrochemical and visual observations during the dynamic polarization shown in Figure 2, it is possible to describe the electrochemical process as follows: starting from the open circuit potential (Eocp $=-1480 \mathrm{mVSCE}$ ), current densities increase significantly until about $200 \mathrm{mVsCE}$ above Eocp. After this period, in the absence of the monomer (curve a), a porous oxide film grows and the E-i response shows a tendency to attain a limiting current, which indicates that the process is controlled by the migration of $\mathrm{Al}^{3+}$ and $\mathrm{O}^{2-}$ ions in the oxide film on the aluminum electrode. The oxide growth proceeds until higher potentials (namely $2000 \mathrm{mVSCE}$ ).

The situation changes when pyrrole is present in the solution (curve b). Point $A$ represents the open circuit potential. Between $A$ and $B$ the behavior is similar in both electrolytes, i.e., the aluminum oxide film grows on the electrode surface. However, when the oxidation potential of the monomer is achieved (point $B$, about $550 \mathrm{mVSCE}$ ), termed polymerization potential (Epol), the polymerization reaction becomes preferential and polypyrrole deposits start to appear

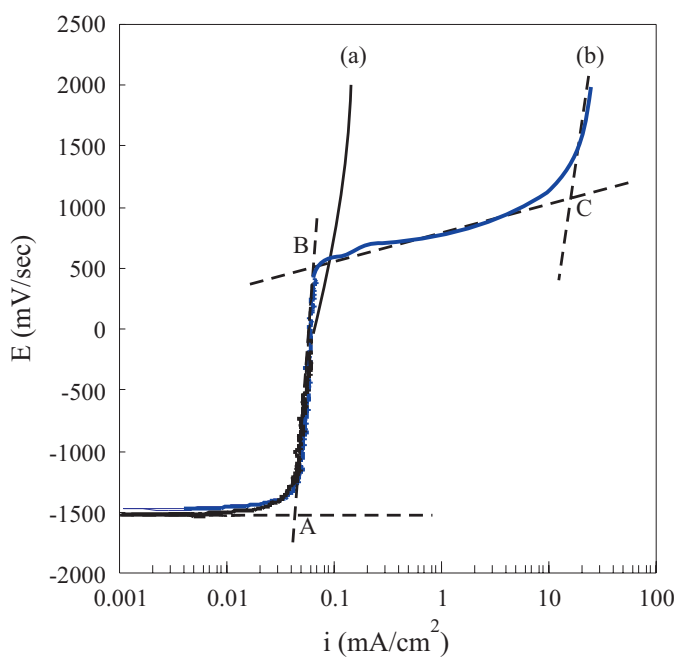

Figure 2. Anodic polarization curves for aluminum electrodes in (a) $0.1 \mathrm{M}$ SDBS electrolyte (no pyrrole) and (b) 0.1M PY:0.1M SDBS electrolyte. Scan rate: $2 \mathrm{mV} / \mathrm{s}$.

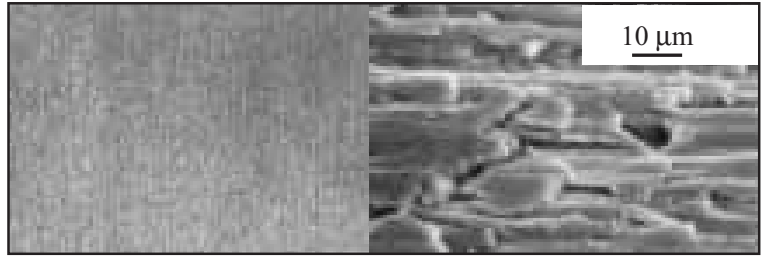

(a)

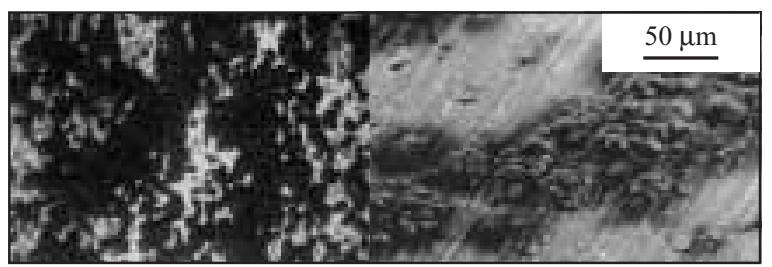

(b)

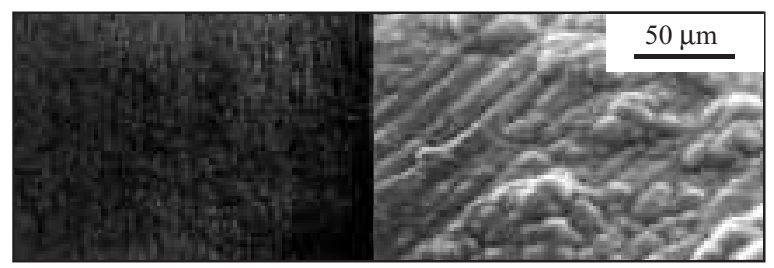

(c)

Figure 3. Optical (left) and scanning electron micrographs (right) of the aluminum electrodes at different potentials of the anodic polarization curve in 0.1 M PY:0.1 M SDBS solution: (a) $\mathrm{E}=600 \mathrm{mVsce}$; (b) $\mathrm{E}=1000 \mathrm{mVsce}$; (c) $\mathrm{E}=1600 \mathrm{mVsce}$. Images reveal formation of agglomerates (clusters) in (b) and continuous film of polypyrrole in (c).

on the electrode surface, which is accompanied by a rapid increase in the current density. In this stage, it is believed that the polymerization conditions increase the flaws density in the oxide film, thus allowing polymerization to take place. At point $C$, the increase in polymer film thickness is responsible for the nearly constant current.

With the sequence of the dynamic polarization, polymer nuclei present three-dimensional (3-D) growth, which occurs faster than the increase of the nuclei population density. At some stage, PPY nuclei spread over the surface, forming agglomerates of polymer termed polypyrrole clusters. These merge with adjacent clusters to form a black polymer film, which covers the macroscopic surface of the electrode. This process is revealed in Figure 3.

The behavior for the potential during the galvanostatic synthesis of polypyrrole is shown in Figure 4. As soon as the current is applied, small polypyrrole deposits (nuclei) develop rapidly over the electrode surface. It is suggested that a fast generation of oligomers occurs, followed by immediate nucleation at a limited number of sites (flaws). These nuclei

Polímeros: Ciência e Tecnologia, vol. 11, no 3, p. 142-148, 2001 


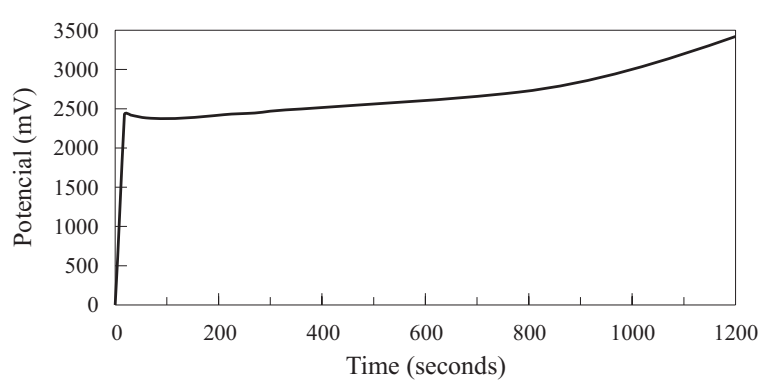

Figure 4. Potential-time behavior during the electrochemical synthesis of the PPY/SDBS film on aluminum under $2 \mathrm{~mA} / \mathrm{cm}^{2}$.

grow to form clusters, which merge with adjacent nuclei and clusters to form a continuous black polymer film, which covers the macroscopic electrode surface. The absence of an induction time, common for oxidisable metal electrodes, may be due to the presence of the pre-existent air-formed alumina film on the metal surface, which prevents the active dissolution of the metal before polymer nucleation has proceeded.

Scanning electron images of the PPY/SDBS film on aluminum are shown in Figure 5. During the polymerization, polymer films appear to have instantaneous three-dimensional growth of hemispherical deposits, which generate a film of nodular morphology. This morphological appearance is similar to PPY films obtained from different electrolytes ${ }^{[19,20]}$. According to Myrick et al. ${ }^{[21]}$ a spherical growth occurs when the polymer growth proceeds from fixed, finite nuclei with a rate that is independent of the direction of growth, the resulting growth morphology is spherical or hemispherical. Employing an electrolyte of similar composition and indium-tin oxide as substrate, Naoi and co-workers ${ }^{[20]}$ considered a columnar structure for the polypyrrole film formed. However, this structure was not evident in our results.

Frequently occurring different forms of anomalous growth, called "dendrites" by some researchers, as shown in Figure 5(c). These dendrites are emerging structures of polypyrrole which appear over the polymer surface on the electrode. In the work of Unsworth et al. ${ }^{[22]}$, dendritic structures were due to surface adsorption of the $\mathrm{O}_{2}$ bubbles, which is particularly evident at low values of $\mathrm{pH}(<7)$. Where the adsorbed bubbles act as nucleation sites for enhanced growth. Generally, once a dendrite is initiated it grows proportionally faster than the rest of the polymer. In our work, using an electrolyte with $\mathrm{pH}$ around 10, dendrites formation was attributed to high local current densities originated from the flaws present in the air-formed alumina film.

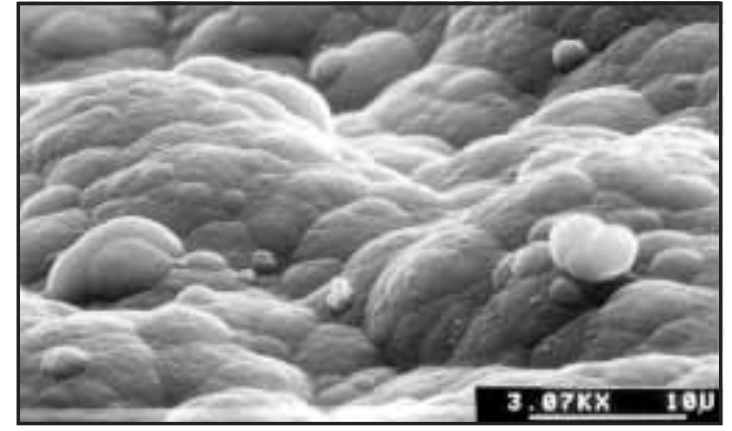

(a)

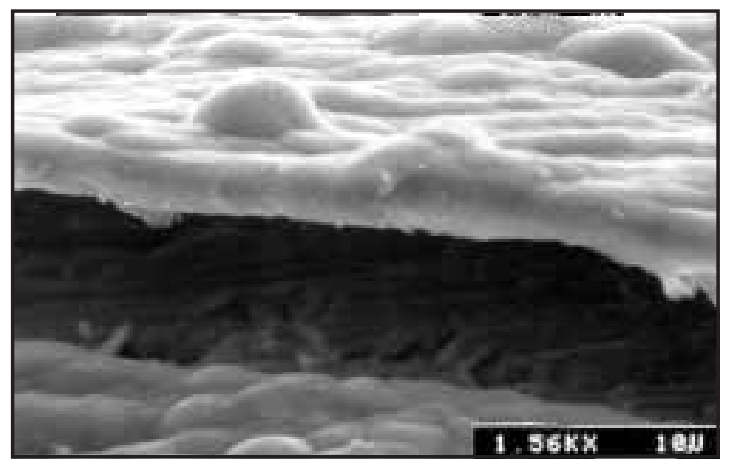

(b)

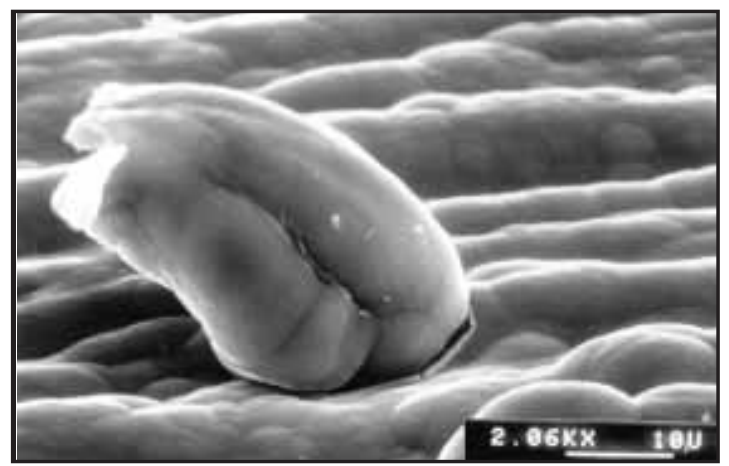

(c)

Figure 5. Scanning electron micrographs of the PPY/SDBS film on aluminum: (a) polymer surface appearance, (b) polymer layer partially detached from the metal surface, and (c) anomalous growth (dendrites) on the polymer surface.

The polymer coating failed in the dry and wet adhesion tape test, presenting classification $1 \mathrm{~B}$ and OB according to ASTM D3359, respectively. The poor adhesion indicates the absence of strong interaction of relatively thick polypyrrole films electrogenerated on aluminum in the presence of surfactant counter-anion.

Figure 6 shows the FT-IR spectrum of the PPY/ SDBS film. The broad peak at $3428 \mathrm{~cm}^{-1}$ corresponds to $\mathrm{N}-\mathrm{H}$ stretch. The incorporation of the counter-anion in the polymer is evidenced by the peaks at 2924 and 


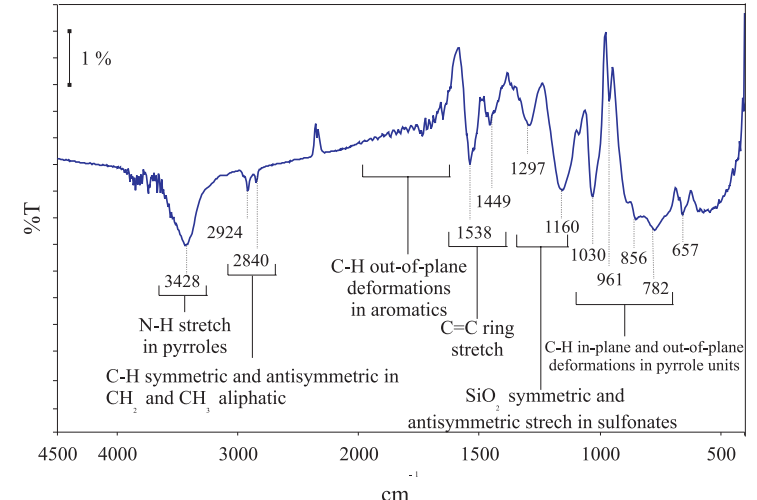

Figure 6. FT-IR spectrum for the PPY/SDBS film galvanostatically generated on aluminum electrodes, measured using $\mathrm{KBr}$ pellets.

$2840 \mathrm{~cm}^{-1}$, assigned to aliphatic- $\mathrm{CH}_{3}$ and $-\mathrm{CH}_{2}$, related to the alkyl chain attached to the benzene ring of the dodecylbenzene sulfonate anion. Further evidence of the presence of this anion in the polymer film is revealed by peaks at $1297 \mathrm{~cm}^{-1}$ and $1660 \mathrm{~cm}^{-1}$, which may be assigned to $\mathrm{SO}_{2}$ stretch in sulphonates ${ }^{[23]}$. The band around $2350 \mathrm{~cm}^{-1}$ was considered an artifact. An interesting feature to be considered is a strong $\mathrm{C}-\mathrm{H}$ peak at $720 \mathrm{~cm}^{-1}$, detected in the pyrrole (monomer) spectrum, but absent in the polymer spectrum. According to Iroh and $\mathrm{Su}^{[24]}$, this peak is assigned to $\mathrm{C}-\mathrm{H}$ wag vibrations arising from adjacent 2,5 hydrogen atoms on the pyrrole ring, which disappear during the oxidative coupling (anodic polymerization) of pyrrole.

In the XPS survey spectrum for the PPY/SDBS film, Figure 7, carbon, nitrogen, oxygen and sulfur were detected. The fitting data for the $\mathrm{C} 1 \mathrm{~s}$ spectra, Figure 8(a), show its deconvolution leads to four main components at about $284.0 \pm 0.1 \mathrm{eV}, 285.5 \pm 0.2$ $\mathrm{eV}, 286.1 \pm 0.1 \mathrm{eV}$ and $287.6 \pm 0.2 \mathrm{eV}$, which may be attributed to $\beta \mathrm{C}, \alpha \mathrm{C}, \mathrm{C}-\mathrm{O}, \mathrm{C}=\mathrm{O}$ groups respectively. From the literature ${ }^{[25]}$, many common nitrogen funcionalities give N1s binding energies (BEs) in the narrow region of 399-401 eV. For polypyrrole films and powders, deconvolution of the N1s signal may lead to three components associated with various intrinsic oxidation states and protonation levels: imine-like $(=\mathrm{N}-)$, amine-like $(-\mathrm{NH}-)$ and positively charged nitrogen atoms $\left(-\mathrm{N}^{+} \mathrm{H}-\right)$, corresponding respectively to BEs about $397.8 \mathrm{eV}, 399.7$ and $>400.5 \mathrm{eV}^{[26]}$. The $\mathrm{N} 1 \mathrm{~s}$ core-level spectrum, Figure 8(b), reveals the presence of a major component at a $\mathrm{BE}$ of $400.1 \mathrm{eV}$, which is assigned to the neutral amine nitrogen component. The BE tail was deconvoluted to a peak at about $402.0 \mathrm{eV}$, corresponding to the positive charged nitrogen. The ab-

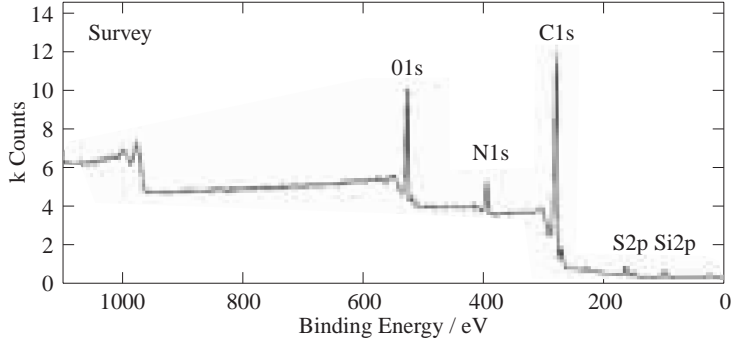

Figure 7. XPS survey spectrum of the PPY/SDBS polymer film galvanostatically deposited on aluminum electrode

sence of the imine-like nitrogen (=N-) at $397.8 \mathrm{eV}$ may indicate that the protonation of PPY occurs preferentially at imine groups ${ }^{[27]}$. The more electron deficient nitrogen species may be attributed to delocalisation of electron density from polypyrrole ring, associated with the formation of electronic defects (polarons and bipolarons). Protonation level, $\left[\mathrm{N}^{+}\right] /[\mathrm{N}]$ ratio, of 0.26 was found and the $[\mathrm{S}] /[\mathrm{N}]$ ratio was greater than the $\left[\mathrm{N}^{+}\right] /[\mathrm{N}]$ ratio, which suggests that substantial amounts of the electrolyte remain in the polymer film despite the extensive washing procedure employed after polymerization.

The polymer film was mechanically removed from the electrode and the electrode surface investigated. The XPS analysis of the aluminum substrate beneath the polymer film revealed the presence of carbon, oxygen, nitrogen, sulfur and aluminum. The presence of nitrogen suggests that a colorless poly-

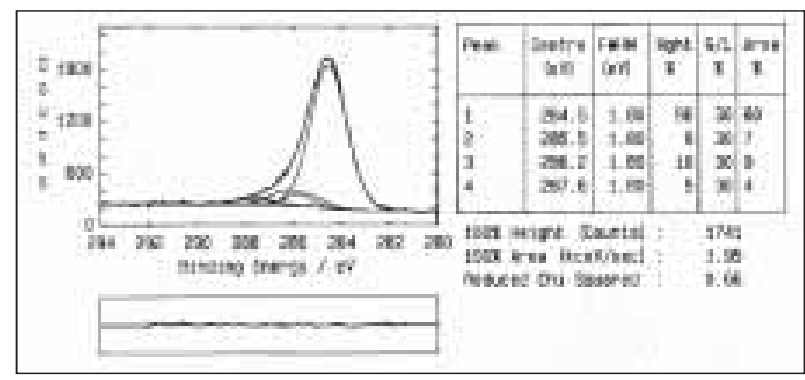

(a)

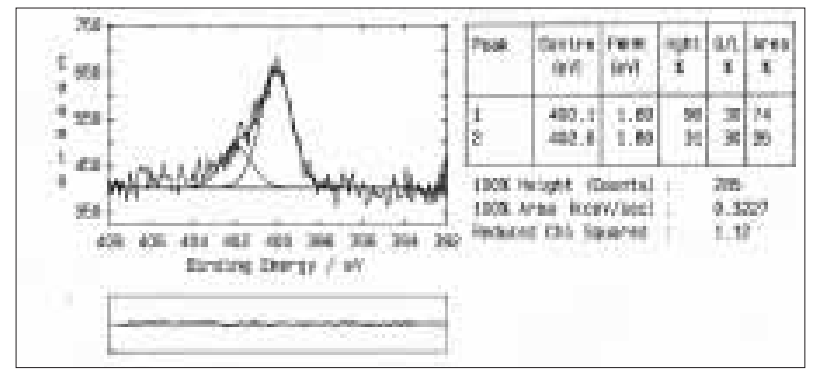

(b)

Figure 8. C1s (a) and N1s (b) core-level spectra for the PPY/SDBS polymer film galvanostatically generated on aluminum electrode. 


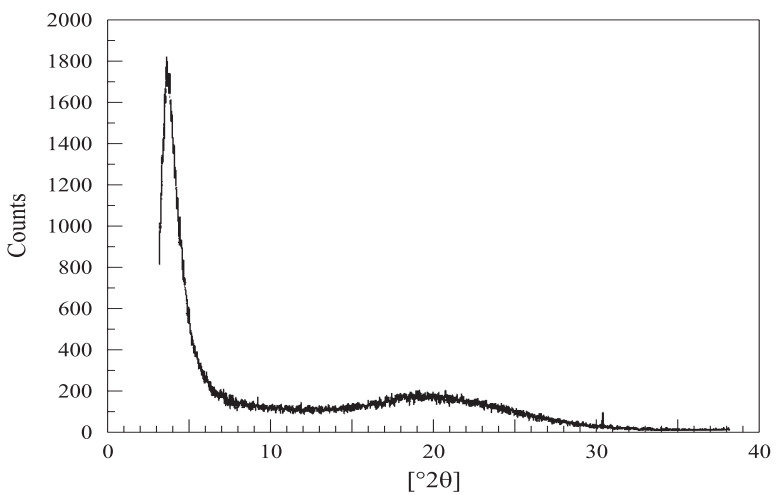

Figure 9. X-ray diffraction spectra for PPY/SDBS film on aluminum.

mer film, probably formed during the early stages of polymerization, remains attached to the metal after removal of the black polymer film.

The diffractogram for PPY/SDBS films (Figure 9) shows maximum broad scattering, characteristic for polypyrrole films ${ }^{[28]}$, which indicates a highly amorphous structure. According to Warren et al. ${ }^{[29]}$, it is possible to distinguish the presence of two types of solid state order, one concerned with the polymer backbone $\left(18^{\circ} \leq 2 \theta^{\circ} \leq 25^{\circ}\right)$ and the other associated with broad distribution of the scattered intensity at about $2 \theta=20^{\circ}$, is typical of PPY/sulfate and sulfonate films ${ }^{(30)}$. The broad scattering around $2 \theta=18.5^{\circ}$ corresponds to a $d$-spacing around $0.48 \mathrm{~nm}$, which may be assigned to scattering of PPY chains at a spacing close to the interplanar Van der Waals distance for aromatic groups ${ }^{[31]}$. The strong low-angle peak $\left(2 \theta=3.8^{\circ}\right)$, with a $d$-spacing about $2.32 \mathrm{~nm}$, correlates with the length of the alkyl-side chain of the surfactant anion ${ }^{[32]}$. The relatively high intensity of the low-angle peak implies a relatively degree of anion order in this system.

\section{Conclusions}

Polypyrrole can be grown in aqueous $0.1 \mathrm{M}$ PY and $0.1 \mathrm{M}$ SDBS on aluminum surfaces under galvanostatic conditions. The mechanism consists in the generation of oligomers with subsequent deposition at the flaws of the pre-existent air-formed alumina film. The polymer growth proceeds covering the macroscopic surface of the electrode. The hemispherical shape of the nuclei originates a polymer film with nodular morphology.

FT-IR spectra revealed the presence of most organic groups expected in polypyrrole films. The oc- currence of the peak corresponding to $\mathrm{N}-\mathrm{H}$ indicates that pyrrole moieties are possibly present.

XPS data revealed that nitrogen occurs in this polymer in two different oxidation states, amine-like and positively charged nitrogen. The protonation occurs preferentially at imine nitrogen groups and the dodecylbenzene sulfonate anion is present in excess related to the positively charged nitrogen.

Although the molecular organization of the generated polymer film was revealed as highly disordered and non-crystalline (liquid-like structure), a relatively high degree of anion order was found.

\section{Acknowledgments}

The authors are grateful to CAPES for the financial support to this research.

\section{References}

1. Arbizzani, C.; Matragostino, M. \& Scrosati, B. - in Handbook of Organic Conductive Molecules and Polymers, H. S. Hawa, Ed; John Wiley \& Sons, Chichester, Vol. 4, 595 (1997).

2. Scrosati, B. - Applications of Electroactive Polymers, Chapman \& Hall, London (1993).

3. Araujo, W. S.; Margarit, I. C. P.; Ferreira, M.; Mattos, O. R. \& Lima Neto, P. - Electrochimica Acta, 46,1307 (2001).

4. Fornari Jr., C. C. M.; Aeiyach, S.; Ferreira, C. A. - Anais do XII Simpósio Brasileiro de Eletroquímica e Eletroanalítica, Gramado, 141 (2001).

5. Moraes, S. R.; Vilca, D. H. \& Motheo, A. J. - Anais do XII Simpósio Brasileiro de Eletroquímica e Eletroanalítica, Gramado, 822, (2001).

6. Scienza, L. C. \& Thompson, G. E. - Anais do Latincorr'2000 $-7^{\text {th }}$ Ibero-American Congress of Corrosion Protection, Cartagena, paper 048-T06 (2000).

7. Lu, W-K and Elsebaumer, R. L. - Anais do Annual Technical Conference, 1276 (1998).

8. Kudoh, Y.; Fukuyama, M. \& Yoshimura, S. - Synth. Met., 66,157 (1994).

9. Kanatzids, M. G. - Chemical Engineering News, 3, 36 (1990).

10. Rodrigues, J.; Otero, T. F.; Grande, H.; Moliton, J. P.; Moliton, A. \& Trigaud, T. - Synth. Met., 76, 301 (1996). 
11. Scienza, L. C. \& Thompson, G. E. - in Anais do $13^{\circ}$ Congresso Brasileiro de Engenharia e Ciência dos Materiais, Curitiba, 3899 (1998).

12. Hulse, P. \& Beck, F. - J. Electrochem. Soc., 137, 2067 (1990).

13. Scienza, L. C.; Thompson, G. E. - in Anais do XII Simpósio Brasileiro de Eletroquímica e Eletroanalítica, Gramado, 481 (2001).

14. Vilca, D. H.; Moraes, S. R. \& Motheo, A. J. - in Anais do XII Simpósio Brasileiro de Eletroquímica e Eletroanalítica, Gramado, 232 (2001).

15. Rodriguez, J.; Grande, H.-J. \& Otero, T. F. - Handbook of Conducting Molecules and Polymers, H. S. Nawa, Ed; John Wiley \& Sons, Chichester, Vol. 2, 415 (1997).

16. De Paoli, M. A.; Peres, R. C. D.; Panero, E. \& Scrosati, B. - Electrochem. Acta, 37, 1173 (1992).

17. Mitchell, G. R. \& Geri, A. - J. Phys. D: App. Phys., 20, 1346 (1987).

18. Ferreira, C. A.; Aeiyach, S.; Delamar, M. \& Lacaze, P. C. - Surf. Interf. Anal., 20, 749 (1993).

19. Sutton, S. J. \& Vaughan, A. S. - Polymer, 36, 1849 (1995).

20. Naoi, K.; Oura, Y.; Maeda, M. \& Nakamura, S. J. Electrochem. Soc., 142, 417. = 15 (1995)

21. Myrick, M. L.; Noll J. D. \& Nicholson, M. A. J. Electrochem. Soc., 1998, 145, 179.
22. Unsworth, J.; Innis, P. C.; Lunn, B. A.; Jin, Z. \& Norton, G. P. - Synth. Met., 53, 59 (1992).

23. Su, W. \& Iroh, J. O. - Polymer Preprints, 39, 159, (1998).

24. Iroh, J. O. \& Su, W. - J Appl. Pol. Sc., 66, 2433 (1997).

25. Briggs, D. \& Seah, M. P. - Practical Surface Analysis by Auger and X-ray Photo-electron Spectroscopy, John Wiley \& Sons, Chichester, Vol. 3, 363 (1987).

26. Kang, E. T.; Neoh, K. G. \& Tan, K. L. - Handbook of Conducting Molecules and Polymers, H. S. Nawa, Ed; John Wiley \& Sons, Chichester, Vol. 3, 121 (1997).

27. Tan, K. L.; Tan, B. T. G. \& Neoh, K. G.- J. Mat. Sc., 27 , 4056 (1992).

28. Saunders, B. R.; Murray, K. S.; Fleming, R. J.; Cervini, R. \& Allen, N. S. - in Handbook of Organic Conductive Molecules and Polymers, H. S. Nawa, Ed; John Wiley \& Sons, Chichester, Vol. 3, 633 (1997).

29. Warren, L. F.; Walker, J. A.; Anderson, D. P.; Rhodes, C. G. \& Buckey, L. J. - J. Electrochem. Soc., 36, 2286 (1989).

30. Wernet, W.; Monkenbusch, M. \& Wegner, G. Makromol. Chemie, Rap. Comm. 5, 157 (1984).

31. Wynne, R. J. \& Street, G. B. - Macromolecules, 18, 2361 (1985).

32. Wegner, G. \& Ruhe, J. - Faraday Discuss. Chem. Soc., 88, 333 (1989).

Recebido: $27 / 01 / 01$

Aprovado: 11/10/01 